\section{Authors' reply: Nonselective nonsteroidal anti-inflammatory drugs and increased cardiovascular events: stress could be the explanation}

Christopher J. Hawkey

Wolfson Digestive Diseases Centre, University Hospital, Nottingham, UK

Dr Sutton [1] is right to consider the broad picture, although some of the associations he suggests are on present evidence, somewhat speculative. I would like to stress that our paper was not written to undermine or attack nonsteroidal anti-inflammatory drugs (NSAIDs) but to contribute to a balanced assessment of their benefits and risk. In this context, although we did not study selective cyclo-oxygenase (COX)-2 inhibitors, our data taken with that of others, suggest that myocardial infarction is not necessarily a price to pay for the gastrointestinal benefits of cyclo-oxygenase selectivity.

\section{Reference}

1 Sutton JA. Nonselective nonsteroidal anti-inflammatory drugs and increased cardiovascular events: stress could be the explanation. Br J Clin Pharmacol 2007; 501.

\section{Received}

14 June 2006

Accepted

14 June 2006

Published OnlineEarly

20 November 2006

\section{Correspondence}

Professor Christopher J. Hawkey, Wolfson Digestive Diseases Centre, University Hospital, Nottingham NG7 2UH, UK. E-mail: cj.hawkey@nottingham.ac.uk

DOI:10.1111/j.1365-2125.2006.02788.x

\section{Authors' reply: Nonselective nonsteroidal anti-inflammatory drugs and increased cardiovascular events: emotional stress could be the explanation}

Kathleen M. Knights, ${ }^{1}$ Arduino A. Mangoni ${ }^{1}$ \& John O. Miners ${ }^{1,2}$ 'Department of Clinical Pharmacology, Flinders University and ${ }^{2}$ Flinders Medical Centre, Bedford Park, Adelaide, Australia

We noted with interest the comments of Dr Sutton [1] that 'a Google search on aldosterone, stress, mood pro- duced '52 000 English or French pages' in 0.33 s' and that our paper [2] 'made no mention of stress as a possible cause of increases in aldosterone during NSAID treatment'. Our research [2] was conducted in vitro using human kidney (and liver) microsomes and demonstrated that nonselective NSAIDs inhibit the glucuronidation of aldosterone, predicating an increase in plasma and tissue (renal) aldosterone concentration in vivo. To suggest that stress is an explantion for our in vitro data indicates that Dr Sutton either did not read or understand the article and its conclusions. Although aldosterone synthesis and secretion is regulated principally by angiotensin II, extracellular potassium and ACTH we concur with Dr Sutton that other factors can stimulate or inhibit aldosterone production in vivo including catecholamines, 5-hydroxytryptamine, heparin and vasoactive intestinal polypeptide [3]. Undoubtedly aldosterone is a key cardiovascular hormone contributing to the pathophysiology of heart failure [3] and the development of hypertension [4]. The potential for a synergistic effect of NSAIDs and 'stress' on aldosterone concentration in vivo might lead us to conclude that in stressful situations the adage 'take an aspirin and lie down' should be revised simply to 'lie down'!

\section{References}

1 Sutton JA. Nonselective nonsteroidal anti-inflammatory drugs and increased cardiovascular events: stress could be the explanation. Br J Clin Pharmacol 2007; 501.

2 Knights KM, Mangoni AA, Miners JO. Nonselective nonsteroidal anti-inflammatory drugs and cardiovascular events: is aldosterone the silent partner in crime? Br J Clin Pharmacol 2006; 61: 738-40.

3 Odedra K, Ferro A. Neurohormones and heart failure; the importance of aldosterone. Int J Clin Prac 2006; 60: 835-46.

4 Vasn RS, Evans JC, Larson MG, Wilson PW, Meigs JB, Rifai N, Benjamin EJ, Levy D. Serum aldosterone and the incidence of hypertension in nonhypertensive persons. N Engl J Med 2004; 351: 33-41.

\section{Received \\ 14 June 2006 \\ Accepted}

14 June 2006

Published OnlineEarly

20 November 2006

\section{Correspondence}

Dr K. M. Knights, Department of Clinical Pharmacology, Flinders University, Bedford Park, Adelaide, Australia. E-mail: kathie.knights@flinders.edu.au 